Supplement of Adv. Sci. Res., 17, 227-253, 2020

https://doi.org/10.5194/asr-17-227-2020-supplement

(C) Author(s) 2020. This work is distributed under

the Creative Commons Attribution 4.0 License.

(c) (1)
Advances in

Science \& Research

Open Access Proceedings

Supplement of

\title{
Assessing groundwater irrigation sustainability in the Euro-Mediterranean region with an integrated agro-hydrologic model
}

Emiliano Gelati et al.

Correspondence to: Emiliano Gelati (emiliano.gelati@geo.uio.no)

The copyright of individual parts of the supplement might differ from the CC BY 4.0 License. 


\section{S1 Simulated groundwater depletion without water use}

We compute statistically significant groundwater depletion rates estimated from a LISFLOODEPIC simulation where water abstractions are not allowed for any sector. Figure S1 shows the ratios between the latter and depletion rates simulated by including abstractions from all sectors. These ratios indicate the portions of total simulated depletions (Fig. 4a in the main text) that may be attributed to climatic changes or model uncertainties.

\section{Groundwater depletion without water use \\ (\% depletion with all uses)}

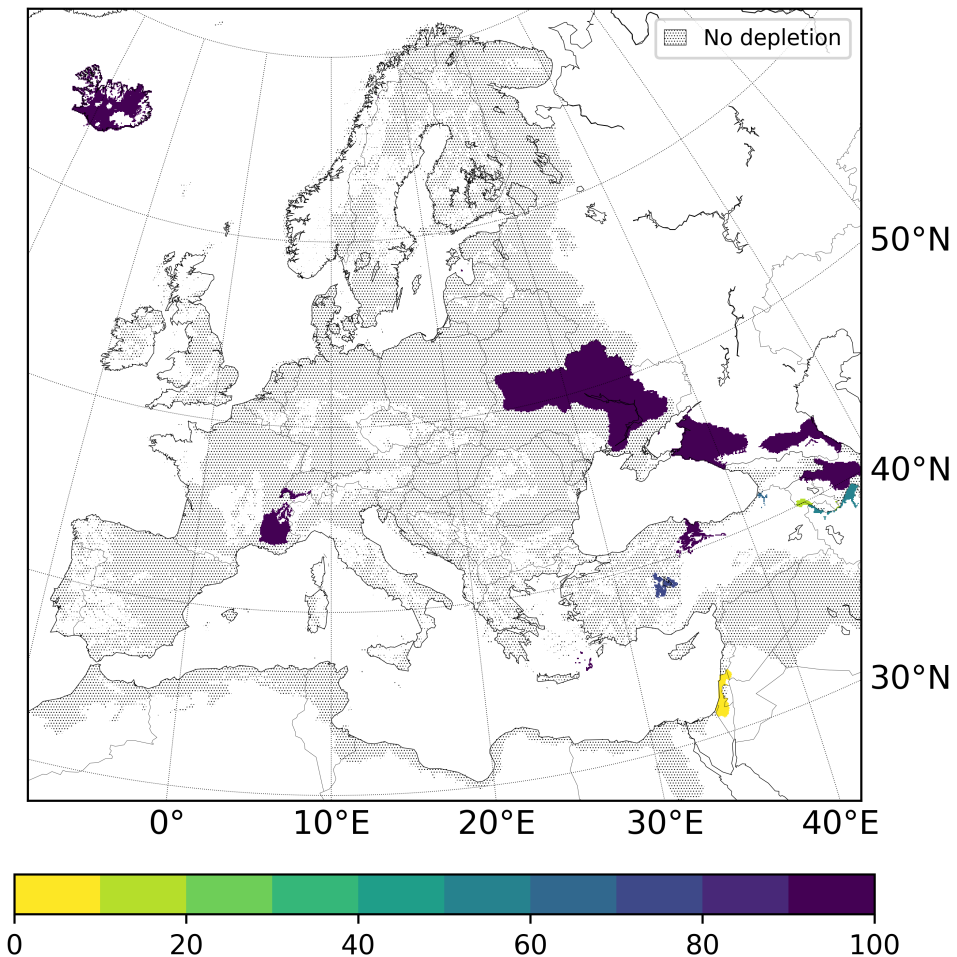

Figure S1: Groundwater depletion simulated in absence of water abstractions as percentage of depletion simulated including abstractions from all uses. Only statistically significant trends are considered. 


\section{S2 Groundwater depletion for Spanish wells with at least 60 monthly observations}

Figure S2 shows groundwater level decline rates estimated for Spanish wells that feature at least 60 monthly observations over the 1990-2017 period. Statistically significant decline trends are detected in the following RBDs (percentage of selected wells): Segura (52\%), Catalonia (44\%), Guadiana (39\%), Guadalquivir (37\%), Tagus (36\%), Júcar (35\%), Guadalete (35\%), Duero (34\%), Ebro (32\%), Western Cantabrian (32\%), Mediterranean Andalusia (25\%), Miño-Sil (22\%), and Eastern Cantabrian (12\%). No decline is detected at wells in Balearic Islands and Tinto RBDs.

Rates shown in Fig. 5 in the main text are computed for wells with at least 120 observations. Comparing Fig. 5 and S2 exemplifies the sensitivity of the groundwater depletion pattern to the well selection criterion.

Groundwater level decline $\left(\mathrm{mm} \mathrm{yr}^{-1}\right)$ from well data

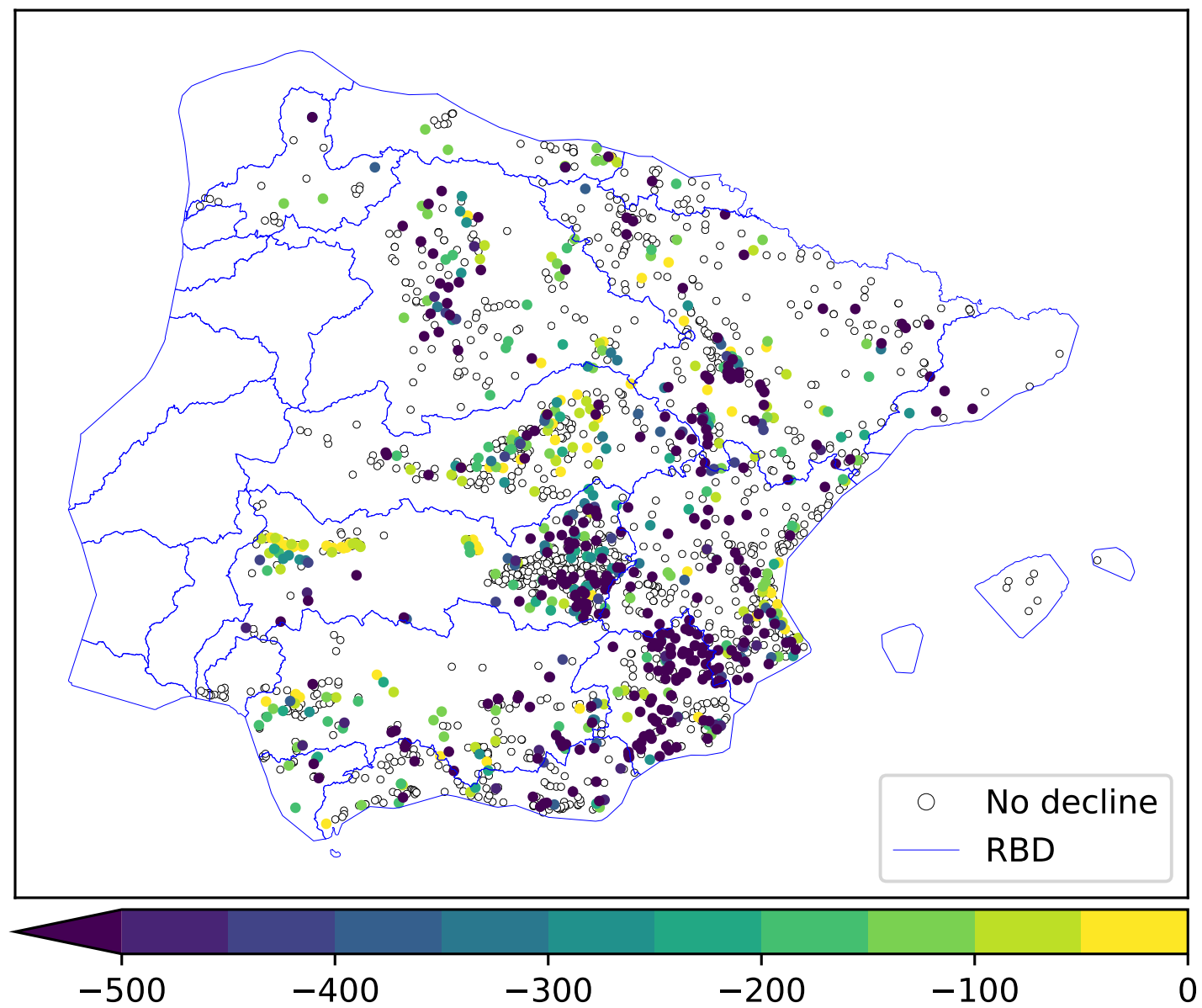

Figure S2: Groundwater depletion rates estimated for Spanish wells whose level measurements span at least 60 months from 1990 to 2017. Displayed rates are statistically significant linear trend slopes. 